\title{
El uso prolongado de anticonceptivos orales aumenta el riesgo de carcinoma de cuello uterino en mujeres HPV positivas
}

Effect of oral contraceptives on risk of cervical cancer in women with human papillonavirus infection:the IARC multicentric casecontrol study. Moreno V, Bosch FX, Muñoz N, y cols. Lancet 2002; 359:1085-92.

\section{Objetivo}

Evaluar la influencia del consumo de anticonceptivos orales (ACO) sobre el riesgo de carcinoma epidermoide de cuello uterino (CECU) en mujeres infectadas por Papilomavirus humano (HPV).

\section{Diseño}

Estudio caso-control ${ }^{\star}$ que reúne los datos individuales de ocho estudios con este diseño.

\section{Lugar}

Tailandia, Filipinas, Marruecos, Brasil, Perú, Paraguay, Colombia y España.

\section{Participantes}

De los estudios mencionados, se incluyeron solo los casos y controles HPV-DNA positivos evaluado por PCR (MY09/11 o GP5+/GP6+ según el estudio).Los casos fueron pacientes con CECU confirmado por histología, salvo en Colombia y España que se incluyeron pacientes con Carcinoma In Situ (CIS).Los controles fueron hospitalarios en todos los estudios salvo en Colombia y España donde fueron poblacionales.

\section{Evaluación de los factores de riesgo}

Se realizaron encuestas y se consultó sobre el uso de ACO, tiempo de uso, compuesto utilizado y tiempo sin uso.Se recogieron también, datos de potenciales confundidores. ${ }^{\star}$

Medición de los resultados principales

Se estimó la asociación a la exposición a ACO mediante Odds Ra- tios* (ORs) ajustados por potenciales confundidores con sus correspondientes intervalos de confianza, mediante un modelo de regresión logística.

\section{Resultados principales}

De las mujeres originalmente incluidas en los estudios, 1465 de 1561 CECU (94\%), 211 de 292 CIS (72\%) y 255 de 1916 controles (13\%) fueron HPV-DNA positivos. El uso de ACO no se asoció con la positividad para HPV (OR=0,75; IC95\% 0,39-1,39). La totalidad de las mujeres HPV positivas que tomaron ACO presentaron alrededor de 1,5 veces más probabilidad de desarrollar CECU que las que no presentaban ese antecedente. Sin embargo, los estudios eran algo heterogéneos $(p=0.052)$

Las mujeres que tomaron ACO por menos de 5 años no presentaron asociación con CECU con respecto a las que nunca tomaron, pero sí en caso de haberlos tomado por más de 5 años ( $y$ en forma creciente a mayor tiempo de exposición), sin que se registre una importante variación según el tiempo transcurrido desde que se dejó de tomar.Esta asociación fue homogénea entre los distintos estudios y entre estudios de CECU y CIS.

\begin{tabular}{l|l}
\hline Exposición a ACO en mujeres HPV & \\
\hline Totalidad de mujeres & OR de CECU (IC95\%) \\
\hline ACOpor menos de 5 años & $1,42(0,99-2,04)$ \\
\hline ACO entre 5 y 9 años & $0,73(0,52-1,03)$ \\
\hline
\end{tabular}

\section{Conclusiones}

El uso de ACO a largo plazo podría ser un cofactor que incrementase el riesgo de CECU en mujeres infectadas por HPV y esto debería ser considerado en los programas de rastreo.

Fuente de Financiamiento: agencias internacionales (OPS, Comunidad Europea, etc)

\section{Comentario}

Es sólida la evidencia que define a la infección por HPV como una causa necesaria, aunque no suficiente, para el desarrollo de CECU. Esta definición implica, entre otras cosas, que se requiere la presencia de cofactores para que la infección por HPV pueda llevar a un carcinoma. El presente estudio es el primer diseño de casos y controles* cuyo universo de estudio son mujeres HPV positivas. La postura resulta coherente ya que, una condición fundamental entre los controles consiste en representar una población similar a la de los casos, lo que quedaría invalidado si se incluyeran mujeres HPV negativas.Estas mujeres nunca podrían ser caso, ya que carecen del factor causal necesario conocido.Comprendiendo este punto, y teniendo en cuenta que el diseño de la muestra de controles otorga la capacidad de generalización de un estudio con el presente diseño, debemos tener en cuenta que las conclusiones a las que se arriba, son aplicables solo a las mujeres HPV positivas. Esto es importante dado la repercusión médica y pública debido el generalizado uso de
ACO.-2 Por otro lado, los controles, aunque hospitalarios en la mayoría de los estudios, fueron recolectados evitando motivos de internación que pudieran relacionarse con el consumo de ACO o al desarrollo de CECU.Las diferencias en la asociación que se registra entre distintos estudios se vincula con la baja exposición a los ACO que se existe en poblaciones, como Paraguay, Tailandia y Filipinas. En ellas es posible que otros cofactores sean los que influyan sobre la progresión.

Conclusiones del comentador: La evidencia presentada por el estudio multicéntrico de la IARC parece abonar la teoría de que los anovulatorios, utilizados por más de 5 años, constituyen un cofactor que, en mujeres HPV positivas, incrementaría significativamente el riesgo de padecer un CECU.Por tal razón, estas mujeres deberán ser manejadas en función de su mayor riesgo. Habrá que analizar en el futuro, utilizando los diseños adecuados, si la suspensión del consumo de anovulatorios en estas mujeres, podría reducir el riesgo mencionado.

\section{Dr. Gustavo Amestoy [ Jefe del Servicio de Ginecología.Hospital Universitario Austral ]}

Referencias

1.Brabin L, Barr F.Oral contraceptives and cervical cancer.Lancet 2002; 360(9330):409-10

2.Berrington A, Jha P, Peto J, Green J, Hermon C;UK National Case-Control Study of Cervical Cancer. Oral contraceptives and cervical cancer.Lancet 2002; 360(9330):410

† A través de estas líneas queremos homenajear al Dr Gustavo Amestoy, fallecido recientemente en forma sorpresiva a los 45 años de edad. Conocí a Gustavo Amestoy hace 11 años cuando yo cursaba el quinto año de la carrera de medicina en la Unidad Docente Hospitalaria CEMIC y tengo un lindo recuerdo de él como coordinador de la materia Ginecología y Obstetricia en dicha institución.

Además de ser un docente muy didáctico en su área clínica fue una de las primeras personas que me vinculó con los conceptos de lo que hoy llamamos Medicina Basada en la Evidencia.Recuerdo que nos mostró las guías de la Universidad de McMaster de evaluación crítica de la bibliografía y realmente, sin que yo tuviera muy claro porqué lo hice en aquel momento, me convenció de la conveniencia de fotocopiarlas (todavía las conservo).Fue por esto que varios años después lo hemos invitado a ser uno de nuestros comentadores.

Actualmente se desempeñaba como Jefe del Servicio de Ginecología del Hospital Universitario Austral y como Profesor Titular de Metodología de la Investigación de la Facultad de Ciencias Biomédicas de la misma institución. El Comité Editorial de la revista Evidencia lamenta su prematura desaparición y envía sus condolencias a su familia.Si bien el Dr Amestoy no llegó a ver la versión final de este artículo consideramos que hemos respetado la esencia del mismo y hemos decidido publicarlo confiando que habría sido de su aprobación.

Sergio Terrasa / Comité Editorial 